\title{
Surface AFM Microscopy of Unworn and Worn Samples of Silicone Hydrogel Contact Lenses
}

\author{
J. M. González-Méijome, ${ }^{1}$ A. López-Alemany, ${ }^{2}$ J. B. Almeida, ${ }^{2}$ M. A. Parafita ${ }^{3}$ \\ ${ }^{1}$ Department of Physics (Optometry), School of Sciences, University of Minho, Braga, Portugal \\ ${ }^{2}$ Department of Optics, University of Valencia, Spain \\ ${ }^{3}$ Department of Surgery (Ophthalmology), School of Optics and Optometry, University of Santiago de Compostela, Spain
}

Received 10 October 2007; revised 27 March 2008; accepted 9 April 2008

Published online 00 Month 2008 in Wiley InterScience (www.interscience.wiley.com). DOI: 10.1002/jbm.b.31153

\begin{abstract}
Purpose. To evaluate the qualitative and quantitative topographic changes in the surface of worn contact lenses (CLs) of different materials using atomic force microscopy (AFM). Methods. The topography of five different CL materials was evaluated with AFM over a surface of $25 \mu^{2}$ according to previously published experimental setup. Average roughness $\left(\boldsymbol{R}_{\mathrm{a}}\right)$ and root mean square $(\boldsymbol{R} m \mathrm{~s})$ values were obtained for unworn and worn samples. Results. The $R_{\mathrm{a}}$ value increased for balafilcon $A(11.62-13.68 \mathrm{~nm}$ for unworn and worn samples, respectively), lotrafilcon A (3.67-15.01 $\mathrm{nm}$ for unworn and worn samples, respectively), lotrafilcon B (4.08-8.42 nm for unworn and worn samples, respectively), galyfilcon A (2.81-14.6 $\mathrm{nm}$ for unworn and worn samples, respectively), and comfilcon $A(2.87-4.63 \mathrm{~nm}$ for unworn and worn samples, respectively). Differences were statistically significant for all lenses except $R \boldsymbol{m} s$ and $\boldsymbol{R}_{\mathrm{a}}$ for comfilcon $\mathrm{A}$, and $\boldsymbol{R}_{\mathrm{a}}$ parameter for balafilcon $\mathrm{A}(\boldsymbol{p}>\mathbf{0 . 0 5})$. The least relative increase was observed for some balafilcon A samples and for some of these samples the roughness decreased after the lenses had been worn. Conclusion. The changes in surface roughness between unworn and worn lenses are different for different silicone-hydrogel materials. Overall all CLs increased the degree of surface roughness after being worn, even for very short periods of time. However, for samples of balafilcon A, roughness increases at a lower extent or even can decrease as compared to unworn samples of the same material due to filling of the macropores. (C) 2008 Wiley Periodicals, Inc. J Biomed Mater Res Part B: Appl Biomater 00B: 000-000, 2008
\end{abstract}

Keywords: atomic force microscopy; contact lens; degradation; surface characterization; wear

\section{INTRODUCTION}

A wide spectrum of microscopy and spectroscopy techniques have been applied to the evaluation of contact lens materials during the past decades as it has been summarized in recent literature reports. ${ }^{1-4}$ Conversely, the quantitative evaluation of surface topography in worn contact lenses has been object of less attention, and only a few publications provided detailed description of these parameters in a wide range of materials used in a clinical setting. ${ }^{5}$ However, the surface of the contact lens (CL) can be a key factor in determining ocular surface tolerance. This is particularly important with the advent of some modern CL

Present results are part of the PhD Thesis by JMG-M.

Correspondence to: J. M. González-Méijome (e-mail: jgmeijome@fisica. uminho.pt)

Contract grant sponsor: Science and Technology Foundation (FCT) - Ministry of Science and Superior Education (MCES) (European Social Funding); contract grant

(C) 2008 Wiley Periodicals, Inc.

materials whose surfaces are treated to improve their wettability as in first generation silicone-hydrogel ( $\mathrm{Si}-\mathrm{Hi}$ ) materials. Some of these lenses show more irregular surfaces when observed by microscopic methods as atomic force microscopy (AFM). ${ }^{2,6}$ This technique offers the unique possibility to quantify the roughness of the surface at a nanometric level with high resolution.

Deposit formation has been described as a major factor of deterioration on current contact lenses, including $\mathrm{Si}-\mathrm{Hi}$ materials, as described in several publications, ${ }^{1}$ and it has been shown that lipids and denaturized proteins could be particularly relevant in Si-Hi materials. ${ }^{7}$

The surfaces of unworn lenses had been evaluated by AFM in different studies. ${ }^{2,8,9}$ The same technique has been also used by several authors to evaluate the surface of worn lenses. ${ }^{5,10}$ However, the application of such methodology to worn samples of Si-Hi materials is lacking at present. Given potential role of mechanical impact of some of these materials on the ocular surface, because of their higher elastic modulus, ${ }^{11}$ it is important to evaluate which

NOTE TO AUTHORS: This will be your only chance to review this proof. 
TABLE I. Details of the Contact Lenses Used in the Study

\begin{tabular}{|c|c|c|c|c|c|c|c|}
\hline Brand & USAN Generic Name & EWC $(\%)$ & Ionic (FDA) & Dk (Barrer) & Power $^{\mathrm{a}}(\mathrm{D})$ & Surface Treatment & $\mathrm{CT}(\mathrm{mm})$ \\
\hline Air Optix Night \& Day & Lotrafilcon A & 24 & $\mathrm{No}(\mathrm{I})$ & 140 & -3.00 & Plasma coating & 0.08 \\
\hline Purevision & Balafilcon A & 36 & Yes(III) & 99 & -3.00 & Plasma oxidation & 0.09 \\
\hline Air Optix & Lotrafilcon B & 33 & $\mathrm{No}(\mathrm{I})$ & 110 & -3.00 & Plasma coating & 0.08 \\
\hline Acuvue Advance & Galyfilcon A & 47 & $\mathrm{No}(\mathrm{I})$ & 60 & -3.00 & No & 0.07 \\
\hline Biofinity & Comfilcon A & 48 & $\mathrm{No}(\mathrm{I})$ & 128 & -3.00 & No & 0.08 \\
\hline
\end{tabular}

${ }^{\mathrm{a}}$ Worn lenses had powers between -2.50 and $-3.50 \mathrm{D} ; \mathrm{CT}$, central thickness.

kind of changes can be expected at the surface of $\mathrm{Si}-\mathrm{Hi}$ CL. This information could be relevant to understand the mechanisms of interaction between worn CLs and the ocular surface and to find better explanations for the ocular response to $\mathrm{CL}$ wear.

This study was carried out to quantify the changes observed at the surface of worn $\mathrm{Si}-\mathrm{Hi}$ contact lenses in the hydrated state using the high resolution capability of the AFM.

\section{MATERIALS AND METHODS}

\section{Samples}

Worn samples of Air Optix Night \& Day and Air Optix (Ciba Vision, Duluth, VA), Purevision (Bausch \& Lomb, Rochester, NY), Acuvue Advance (Johnson \& Johnson, Jacksonvile, FL), and Biofinity (Coopervision, CA) were observed with AFM in Tapping Mode using the experimental protocol described in previously published work ${ }^{2}$ and later described in this section to obtain CL surface roughness in the hydrated state. Ten samples of each material were used. All lenses had refractive power between -2.50 and -3.50 diopters (D). Technical details of the lenses

T1 used in this study are listed in Table I. All lenses were worn for 30 days on daily wear basis except Acuvue Advance that was worn only for 15 days as recommended by the manufacturer. Lenses were worn for an average of 10-12 h per day, followed by rubbing, and overnight disinfection. The same multipurpose solution (Renu Multiplus, Bausch \& Lomb, Rochester, USA) was used for daily care purposes with all lenses. No additional cleaning or disinfecting systems was used. Only the anterior surface of each sample was evaluated. Results were compared against control samples of the same materials obtained directly from the original containers. All unworn samples had a power of $-3.00 \mathrm{D}$.

\section{Atomic Force Microscope}

For AFM analysis different samples of each material were placed in a convex holder resting on the inner surface and keeping the lens fully hydrated during the measuring process. The convex face of this holder has been designed to mimic the curvature of the CLs used (approximately $8.6 \mathrm{~mm})$. All the microscopic examinations were carried out in the same room kept at $24^{\circ} \mathrm{C}$ and approximately $50 \%$ relative humidity. All observations were conducted in an aqueous environment using the liquid cell of the AFM (Nanoscope III, Digital Instruments, Santa Barbara, CA). Cantilevers with a nominal force constants of $k=0.58 \mathrm{~N} /$ $\mathrm{m}$ and oxide sharpened $\mathrm{Si}_{3} \mathrm{~N}_{4}$ tips (Olympus, Tokyo, Japan) were used for Tapping Mode imaging.

\section{Quantitative Topographic Analysis}

Average surface roughness $\left(R_{\mathrm{a}}\right)$ and mean-square-roughness $(R m s)$ were obtained from the roughness analysis facility of the Nanoscope III software as we did in previous studies. $^{2,12} R_{\text {a }}$ represents the average distance of the roughness profile to the center plane of the surface profile. Rms represents the standard deviation from the mean surface plane. Both roughness parameters are expressed in nanometers $(\mathrm{nm})$. In this study, we did not include maximum roughness $\left(R_{\max }\right)$ as this parameter represents the maximum high identified within the observed area and does not reflect the actual topography of the lens presenting large variability depending on the targeted area. ${ }^{2}$ Samples were scanned over lengths of $5 \mu \mathrm{m}$ to give a surface area of $25 \mu \mathrm{m}^{2}$. Although this is a very small area considering the full CL surface, it has been shown that provides a good resolution for the identification of the particularities of each material surface with good repeatability. ${ }^{2}$

Values of average roughness $\left(R_{\mathrm{a}}\right)$ and root mean square roughness $(R m s)$ were compared against those obtained for 10 unworn samples of the same materials with a refractive power of $-3.00 \mathrm{D}$.

\section{Statistical Analysis}

Statistical analysis was performed using SPSS Software v.15.0 (SPSS, IL). Normal distribution of variables was previously assessed by Kolmogorov-Smirnov test. When normal distribution of data could not be assumed, MannWhitney nonparametric test for independent samples was carried out in order to compare mean values of roughness ( $R m s$ and $R_{\mathrm{a}}$ ) between worn and unworn samples. Comparisons involving normally distributed variables were performed using independent samples $t$-test. In this case, Levene test was used to assess equality of variances. The level of statistical significant was set at $\alpha=0.05$. 


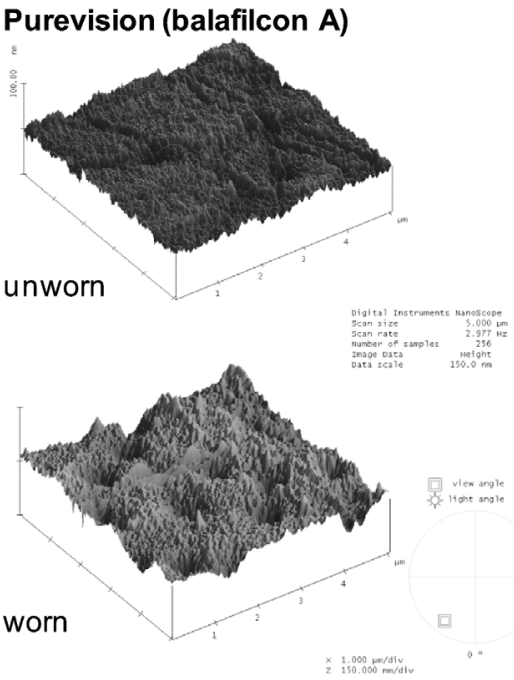

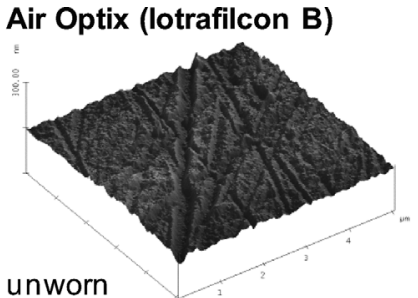

unwor

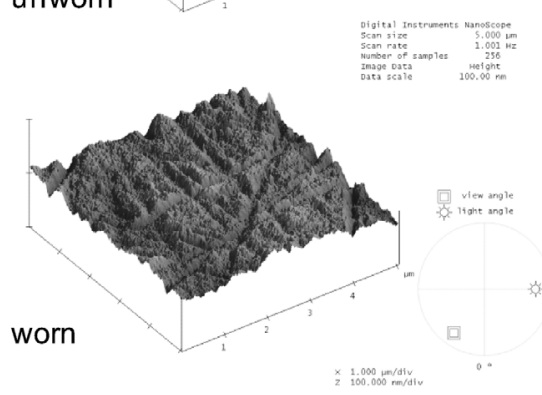

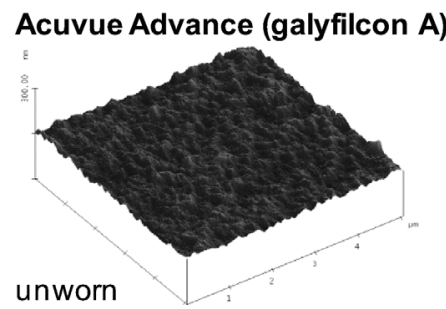
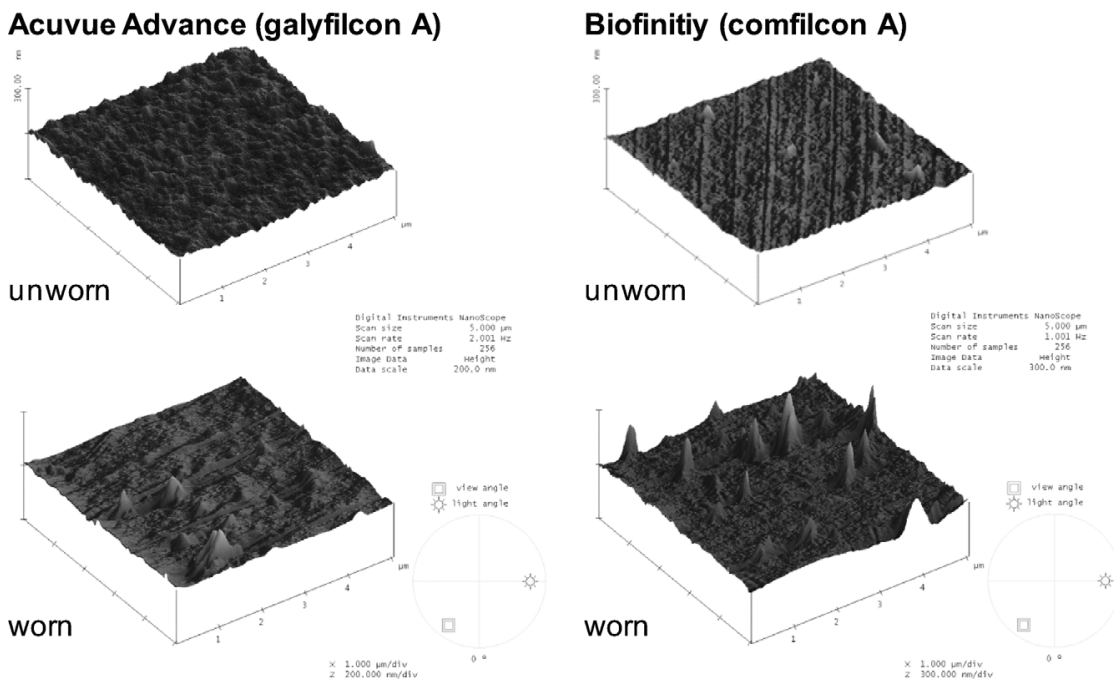

Figure 1. Examples of the qualitative appearance of unworn lenses and worn samples of different materials. [Color figure can be viewed in the online issue, which is available at www.interscience. wiley.com.]

\section{RESULTS}

F1

Figure 1 displays examples of the qualitative appearance of worn samples of lotrafilcon A, balafilcon A, lotrafilcon B, galyfilcon $\mathrm{A}$, and comfilcon A materials. On the top of each image, a microtopograph of an unworn sample is shown for comparison purposes. for the unworn and worn samples. Tables II and III show the results of the statistical comparison for values of Rms and $R_{\mathrm{a}}$, respectively, between unworn and worn lenses.

Overall, all worn lenses presented higher values of $R m s$ and $R_{\mathrm{a}}$ than their unworn reference samples. However, the lens with the initial higher values of roughness (balafilcon A) displays only a modest increase in the roughness parameters compared to the remaining samples whose Rms and

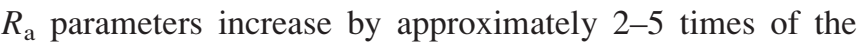
initial value while $R m s$ and $R_{\mathrm{a}}$ values for balafilcon A increase only by 1.25 and 1.17 times, respectively. More-

over, balafilcon A was the only material with a worn sample having lower surface roughness than the unworn reference values. This sample is shown in Figure 3 along with a reference image from an unworn sample. This example is provided to demonstrate that with this lens, it is possible to obtain lower values of roughness in worn lenses than in some unworn samples. It seems apparent that the reduction in the roughness parameters is due to the partial filling of the macropores usually seen in new samples of this material. ${ }^{2,13}$ This made possible that the $R m s$ and $R_{\mathrm{a}}$ values for the unworn sample were higher $(R m s=26.59$ $\left.\mathrm{nm} ; R_{\mathrm{a}}=20.22 \mathrm{~nm}\right)$ than those obtained for the worn sample $\left(R m s=22.01 \mathrm{~nm} ; R_{\mathrm{a}}=17.55 \mathrm{~nm}\right)$ in the example presented in Figure 3.

Images in Figure 4 show how the deposit formation on the CL surface do not necessarily have to distort the characteristic appearance of some CLs. This is illustrated on this figure for balafilcon A and lotrafilcon B materials. This effect can also be observed in three-dimensional images 


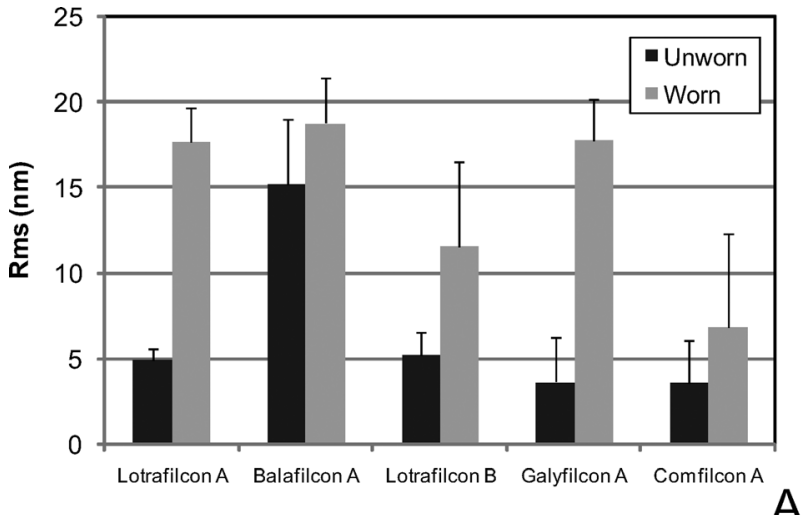

A

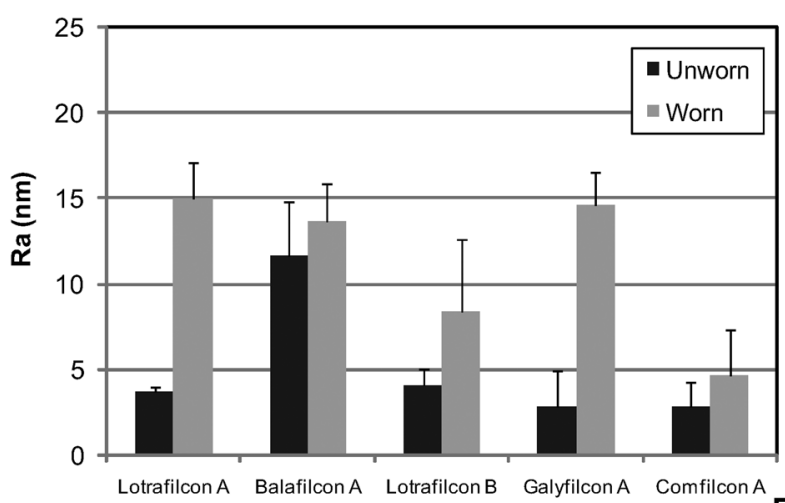

Figure 2. Quantitative parameters of $R m s(\mathrm{~A})$ and $R_{\mathrm{a}}(\mathrm{B})$ for unworn and worn samples of the five CL materials.

provided in Figure 1. Figure 5 shows the qualitative appearance of samples of two different contact lens materials worn by the same patient for $20 \mathrm{~min}$ in one case and for 30 days in other case. It is apparent that the qualitative aspect of both worn samples is not much different. In fact, the quantitative values of roughness are very similar. Five balafilcon A samples worn for $20 \mathrm{~min}$ showed $R m s=$ $16.31 \pm 2.52 \mathrm{~nm}$ and $R_{\mathrm{a}}=11.47 \pm 1.38 \mathrm{~nm}$ compared with $R m s=18.80 \pm 2.56 \mathrm{~nm}$ and $R_{\mathrm{a}}=13.68 \pm 2.21 \mathrm{~nm}$ for the 10 samples of the same material worn for 1 month. On the other side, five samples of comfilcon A worn for 20 min displayed $R m s=4.86 \pm 2.15 \mathrm{~nm}$ and $R_{\mathrm{a}}=3.72 \pm$ $1.47 \mathrm{~nm}$ against $R m s=6.89 \pm 5.42 \mathrm{~nm}$ and $R_{\mathrm{a}}=4.63 \pm$
$2.74 \mathrm{~nm}$ for the 10 samples of the same material worn for 1 month.

\section{DISCUSSION}

AFM is becoming a powerful tool for the characterization of CL material surface. This is particularly important in SCL because this technology allows us to evaluate the lens in the hydrated state without need of preparation or dehydration of the sample. With the advent of Si-Hi materials, and the need for surface treatment in some of them, the relevance of accurate characterization of the surface has increased the use of this technique. In the most recent study conducted using this technique, Guryca et al. ${ }^{14}$ have found a close relationship between the maximum roughness $\left(R_{\max }\right)$ and the equilibrium water content (EWC) of the material, with the $R_{\max }$ value decreasing as the EWC increased. In fact, in previous studies, ${ }^{2,6,15}$ we have found that the Si-Hi lenses lotrafilcon A and B and balafilcon A of relative low EWC present higher surface roughness than Si-Hi materials with higher EWC. However, even lenses with similar EWC as balafilcon A (36\% EWC) and senofilcon A (38\% EWC) have markedly different surface roughness values as seen in this study. So, the findings of Guryca et al. ${ }^{14}$ can be related more to the surface treatment of the low EWC Si-Hi lenses rather than to their low EWC. Rather than a direct effect of low EWC on surface roughness, our published results and unpublished experiences with AFM suggest that conventional hydrogel materials and Si-Hi without surface treatment have smoother surfaces than Si-Hi with surface treatment. ${ }^{2,6,15}$

Beyond the characterization of the new unworn Si-Hi contact lenses mentioned earlier, is the relatively unexplored area of research dealing with the application of the AFM technique to analyze the worn lenses. In the few studies conducted with this purpose, Goldberg et al.,16 observed significant changes in the surface of worn CL. However, their studies were conducted in conventional hydrogel materials while the growth of present contact lens practice relies strongly on $\mathrm{Si}-\mathrm{Hi}$ materials. ${ }^{17}$

Our results show that for the majority of the $\mathrm{Si}-\mathrm{Hi}$ lenses analyzed the surface roughness increases significantly after they had been worn. However, there was a

TABLE II. Comparison of Values of Root Mean Square Roughness Parameter (Rms) for Worn and Unworn Samples of the Same CL Materials

\begin{tabular}{lcrr}
\hline Contact Lens (Material) & Unworn Samples $(n=10)$ & Worn Samples $(n=10)^{\text {Statistical Significance }^{\mathrm{a}}}$ \\
\hline Air Optix Night \& Day (lotrafilcon A) & $4.98 \pm 0.60$ & $17.68 \pm 1.98$ & $<0.001^{\mathrm{a}}$ \\
Purevision (balafilcon A) & $15.19 \pm 3.81$ & $18.8 \pm 2.56$ & $0.021^{\mathrm{b}}$ \\
Air Optix (lotrafilcon B) & $5.27 \pm 1.31$ & $11.59 \pm 4.91$ & $0.002^{\mathrm{b}}$ \\
Acuvue Advance (galyfilcon A) & $3.68 \pm 2.61$ & $17.79 \pm 2.43$ & $<0.001^{\mathrm{b}}$ \\
Biofinity (comfilcon A) & $3.62 \pm 2.39$ & $6.89 \pm 5.42$ & $0.237^{\mathrm{a}}$ \\
\hline
\end{tabular}

Values in $\mathrm{nm}$.

${ }^{a}$ Mann-Whitney nonparametric test for independent samples.

${ }^{\mathrm{b}}$ Independent Sample $t$-test. 
TABLE III. Comparison of Values of Average Roughness Parameter $\left(R_{\mathrm{a}}\right)$ for Worn and Unworn Samples of the Same CL Materials

\begin{tabular}{lrrr}
\hline Contact Lens & Unworn Samples $(n=10)$ & Worn Samples $(n=10)^{\text {Statistical Significance }^{\mathrm{a}}}$ \\
\hline Air Optix Night \& Day (lotrafilcon A) & $3.67 \pm 0.35$ & $15.01 \pm 2.13$ & $<0.001^{\mathrm{b}}$ \\
Purevision (balafilcon A) & $11.62 \pm 3.22$ & $13.68 \pm 2.21$ & $0.157^{\mathrm{b}}$ \\
Air Optix (lotrafilcon B) & $4.08 \pm 0.92$ & $8.42 \pm 4.14$ & $<0.001^{\mathrm{a}}$ \\
Acuvue Advance (galyfilcon A) & $2.81 \pm 2.12$ & $14.6 \pm 1.93$ & $<0.001^{\mathrm{b}}$ \\
Biofinity (comfilcon A) & $2.87 \pm 1.47$ & $4.63 \pm 2.74$ & $0.151^{\mathrm{b}}$ \\
\hline
\end{tabular}

Values in $\mathrm{nm}$.

${ }^{\text {a }}$ Mann-Whitney nonparametric test for independent samples.

${ }^{\mathrm{b}}$ Independent sample $t$-test.

trend toward lower relative increase in roughness parameters for those lens surfaces that were initially more irregular.

Trying to transpose the topographic data to the clinical field, previous studies conducted by Baguet et al. ${ }^{10}$ concluded that the highest the roughness of a material the most prone is to deposit formation. However, in our results the balafilcon A lens with the rougher surface of the lenses analyzed was the lens that demonstrated the lowest relative increase of surface roughness after being worn. Nevertheless, the change in roughness with the use of the lenses should not be considered as the only factor related to the degree of deposit formation on the lenses. In fact, a recent

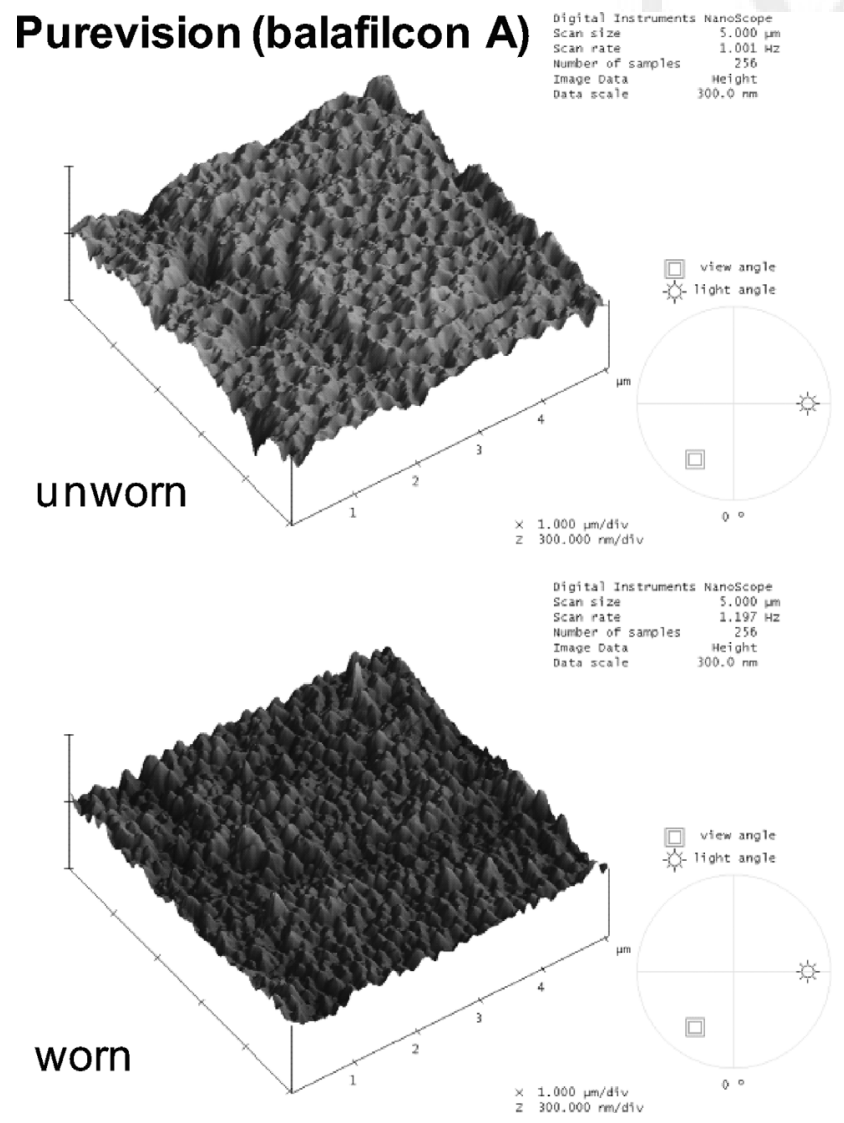

Figure 3. Microtopographic images of the surface of unworn (A) and the corresponding worn sample $(B)$ of balafilcon $A$. [Color figure can be viewed in the online issue, which is available at www. interscience.wiley.com.] study Subbamaran et al. ${ }^{18}$ found a higher amount of lysozyme deposition overtime on balafilcon A compared to other Si-Hi lenses, due indeed to the iconicity of this lens. Along with comfilcon A, balafilcon A was the only material that did not demonstrated significant changes in $R_{\mathrm{a}}$ parameter. This could also be explained not only by the higher variability in roughness among the unworn lenses evaluated, but also to the lowest relative increase of roughness values $(\approx 1.2 \times)$ compared to the other samples $(\approx 2-$ $5 \times)$. The lower values of roughness in comfilcon $A$ and the high variability are also responsible for the absence of statistically significant changes between unworn and worn lenses of this material. On the other hand, galyfilcon $\mathrm{A}$ with a smoother surface for unworn samples displayed a significant increase in the roughness after wear. This could be related to the fact that contact lenses that contain $N$ vinyl pyrrolidone (NVP) moieties are prone to the formation of lipid deposits. ${ }^{19}$ This could explain the relative increase of roughness On galyfilcon A which incorporates in its formulation a derivative of NVP as a so-called internal wetting agent which along with the hydrophobic nature of siloxane, could increase the amount of lipid deposits and the roughness of the material. In the study of Subbaraman et al., galyfilcon A material was the second $\mathrm{Si}-\mathrm{Hi}$ material with higher amount of lysozyme deposits. This study did not evaluate the biochemical nature of the deposits, but recent studies support the high lipid deposition on Si-Hi contact lenses, ${ }^{7}$ fact that could be considered relevant to the increase surface roughness on the worn $\mathrm{Si}-\mathrm{Hi}$ lenses.

The influence of surface roughness on bacterial adhesion to the CLs is far from being understood. For example, there is interest on elucidate if the increase in surface roughness as a consequence of wear as found in this study, could be a risk factor leading to increase ocular infection due to high bacterial attachment to the CLs. Some authors found a higher bacterial adhesion to some $\mathrm{Si}-\mathrm{Hi}$ materials ${ }^{20}$ what seems to corroborate surface roughness as a potential factor for bacterial adhesion to the lenses, explaining it by the fact that organism on rough surfaces are protected against shear forces and cleaning procedures. ${ }^{21}$ Considering that unworn balafilcon A has a rougher surface that all the other currently available $\mathrm{Si}-\mathrm{Hi}$ lenses, that increase roughness after use, it would be interesting to know if this could affect bacterial adhesion and potential contamination of the ocular surface. In this regard, Vermeltfoort et al. reported that CL 


\section{Purevision (balafilcon A)}
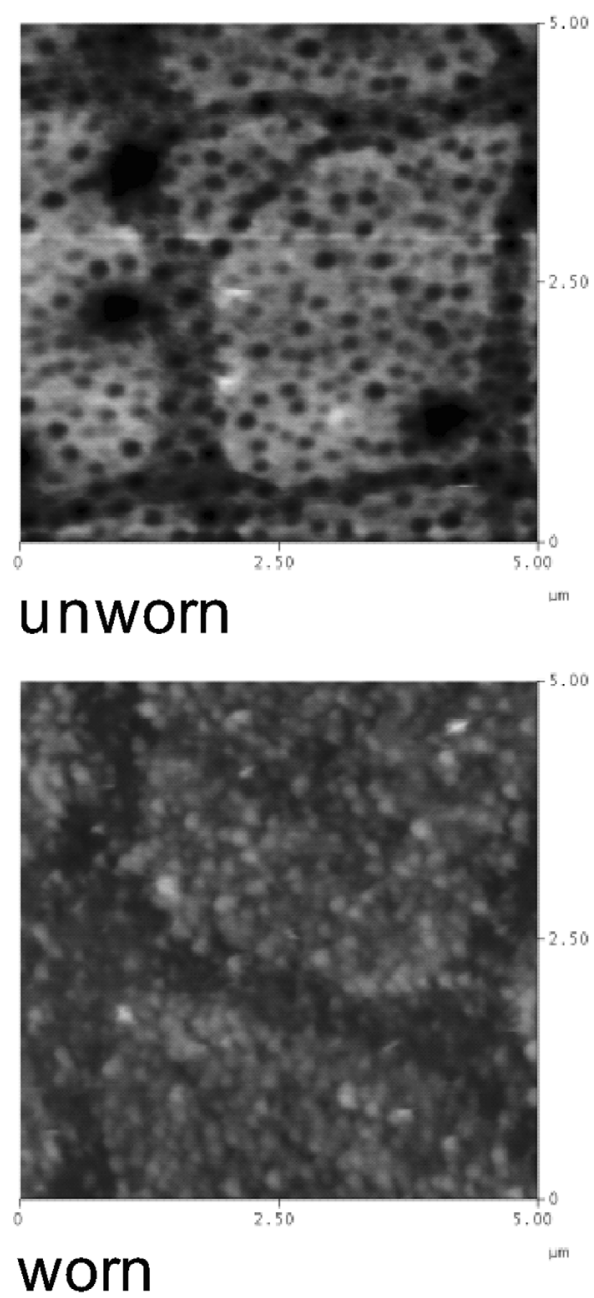

\section{Air Optix (lotrafilcon B)}
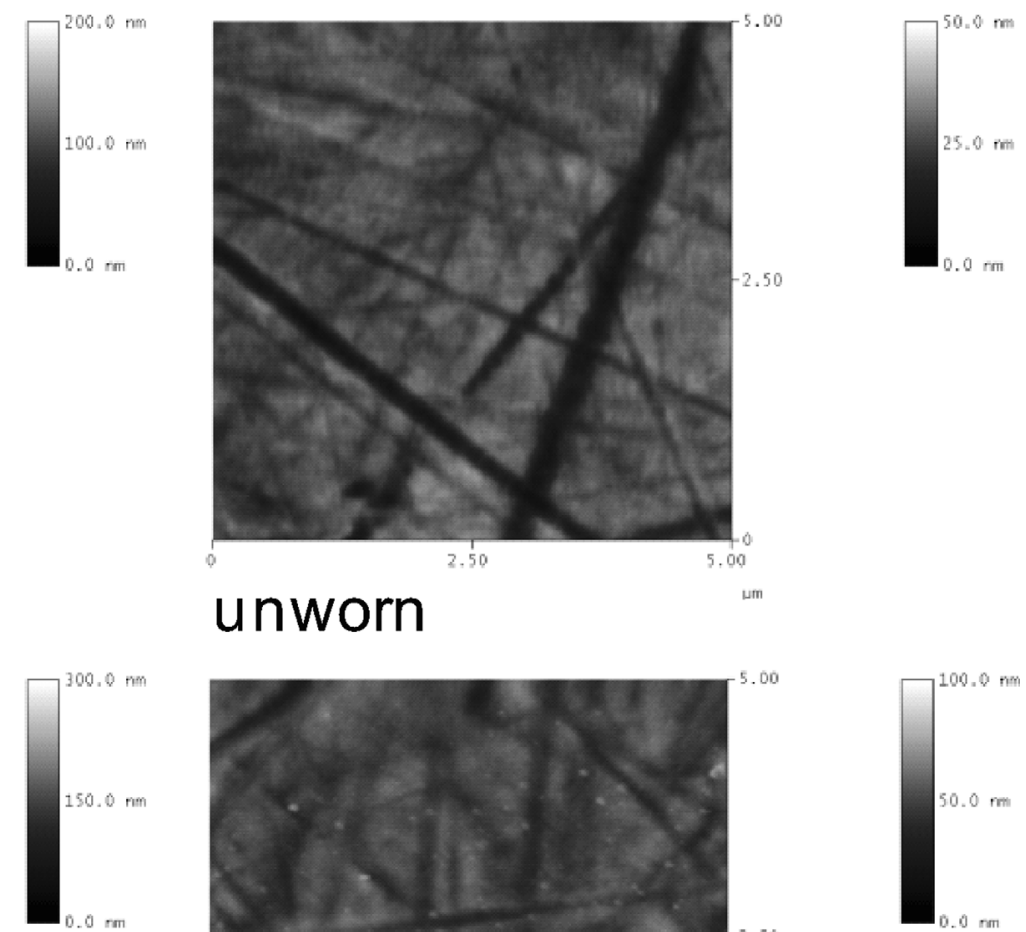

\section{unworn}

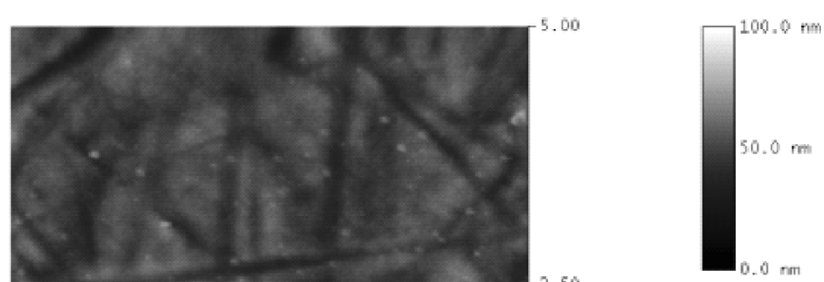

Figure 4. Examples of the qualitative appearance of unworn and worn samples of two different materials (balafilcon A and lotrafilcon B). [Color figure can be viewed in the online issue, which is available at www.interscience.wiley.com.]

materials of different degrees of hydrophilicity and surface roughness did not accounted significantly for the rate of bacterial transfer from the contact lens to the substrate below the lens, explaining that the main contributors were contact time, bacteria strain, and surface hydrophilicity and roughness (higher transfer rate to more hydrophilic substratum and smoother surfaces). ${ }^{22}$

In another study, Vermeltfoort et al. did not find significant changes in the surface roughness of Si-Hi materials after 1 and 4 weeks of wear, while a reduction in the wetting angle was observed. ${ }^{23}$ These facts were accompanied by a general decrease in the adhesion of bacteria to worn lenses compared to new samples. ${ }^{23}$ These results agree with the findings of Boles et al. who concluded that worn disposable CLs restricted the attachment of Pseudomonas aeruginosa compared to new lenses. ${ }^{24}$ Early studies from Duran et al. also support the affinity of new CL materials for bacterial adhesion. ${ }^{25}$ Regarding the lack of significance of increase in surface roughness found by Vermelfoort et al. ${ }^{23}$ in their study, this seems not to be supported by previous research that demonstrated a significant increase in roughness. ${ }^{10,26}$ Our results are very clear in supporting this increase in surface roughness with use. Results from Bruinsma et al. ${ }^{26}$ agree with previous studies showing that wear and overwear of CL do not imply an increase in bacterial adhesion, despite the increase in surface roughness that they have observed, particularly in lenses that had been used beyond the intended replacement schedule. In a study conducted by Michaud et al., overwear of group IV hydrogel CL was associated with an increased level of protein deposits. This increase could be somewhat responsible for the exacerbation of several clinical signs and decrease in visual acuity found by the authors. ${ }^{27}$ The results of Subbaraman et al. also corroborates the increase of protein deposits during a month of CL wear, and this pattern also 


\section{Biofinity (comfilcon A)}
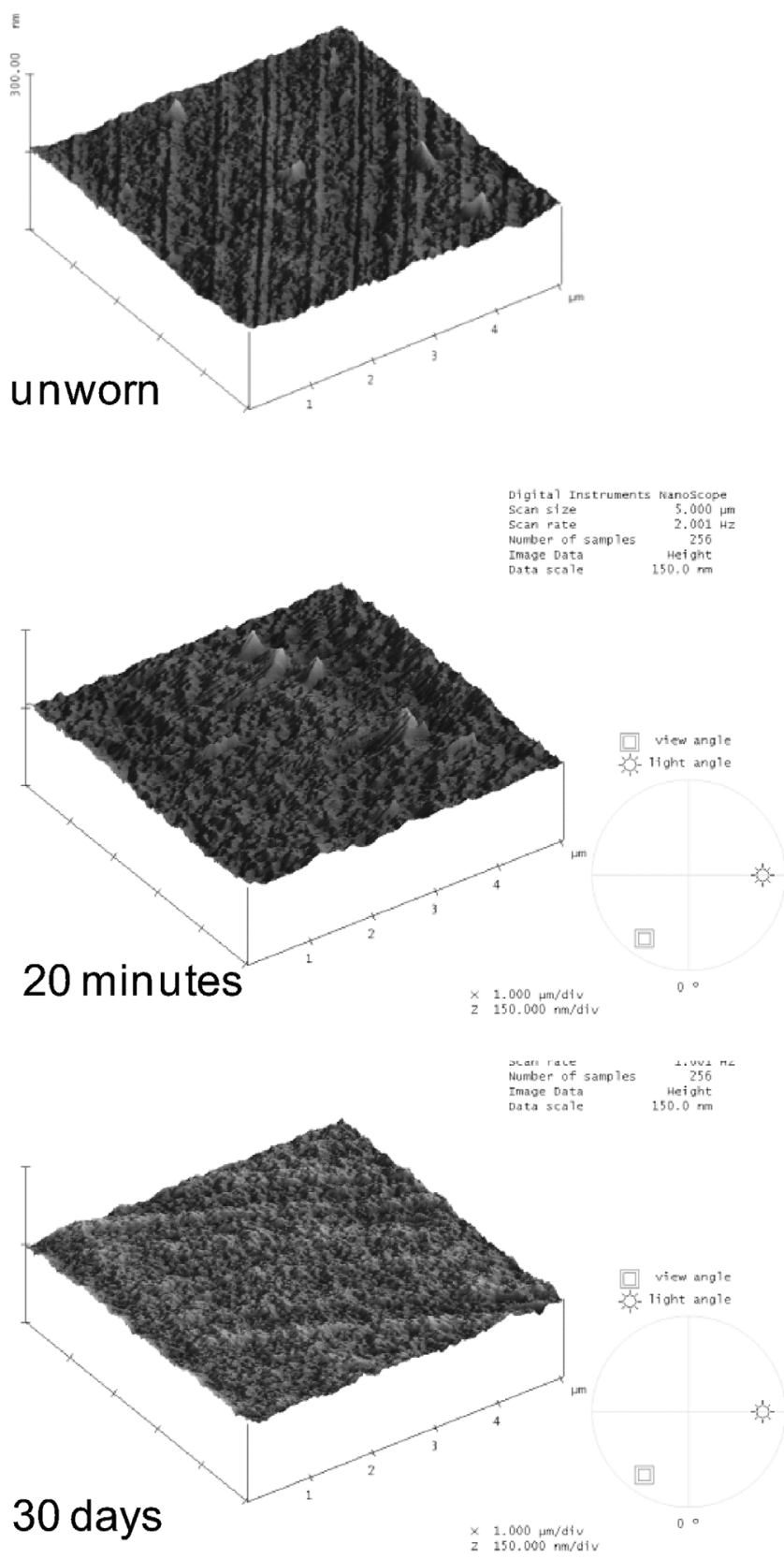

Purevision (balafilcon A)

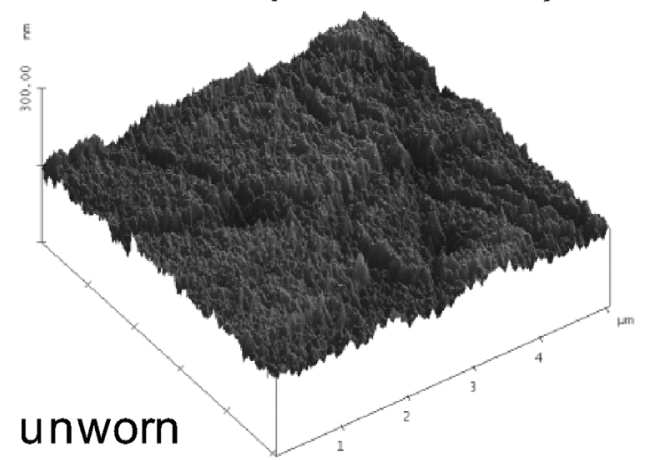

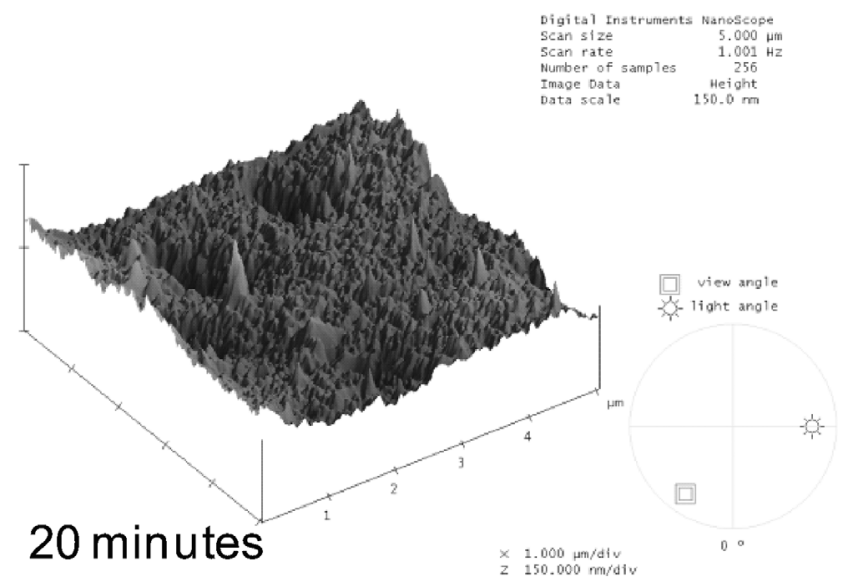

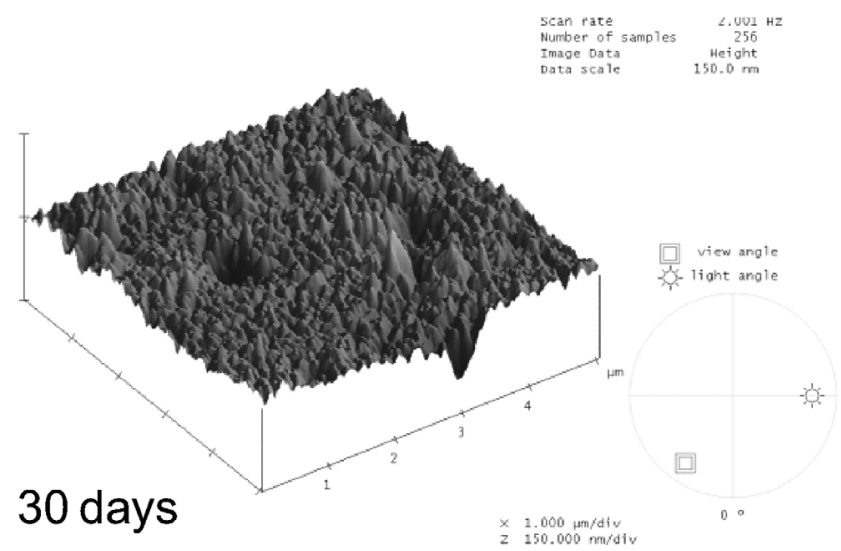

Figure 5. Samples of the same CL material worn for $20 \mathrm{~min}$ and 30 days by the same patients and corresponding reference unworn samples. [Color figure can be viewed in the online issue, which is available at www.interscience.wiley.com.]

affects Si-Hi materials, although at a lower extent compared with conventional (HEMA-based) hydrogels. ${ }^{18}$

Results from Beattie et al. ${ }^{2}$ showed that $\mathrm{Si}-\mathrm{Hi}$ lenses with surface treatment showed a higher level of bacterial attachment than other nontreated $\mathrm{Si}-\mathrm{Hi}$ materials. ${ }^{20}$ The materials compared in that study showed in previous studies conducted by us that balafilcon A presents a significantly higher roughness value than galyfilcon $\mathrm{A}^{2}{ }^{2}$ in agreement with data reported here for unworn samples. In fact, Beattie et al. demonstrated a lower bacterial attach- ment to second generation $\mathrm{Si}-\mathrm{Hi}$ lens without surface treatment (galyfilcon A) compared to first generation surface treated lotrafilcon A. ${ }^{28}$ Even if surface treatment could be a source or surface irregularity, we cannot ensure that the presence of surface treatment itself could be a risk factor for bacterial adhesion. On the light of previous research, this factor seems not to be a determinant one. ${ }^{29}$

In summary, this study shows that deposit formation over disposable $\mathrm{Si}$-Hi materials create a relatively thin layer that in some cases is unable to mask the typical pattern of some 
CLs. Overall this deposit build-up increases the roughness of the surface by twofold but can be a factor for the surface to become smoother on worn $\mathrm{Si}$-Hi contact lenses that are characterized by high roughness prior to be worn.

We thank M. Planes and J.L. Moya (Polytechnic University of Valencia) for their assistance with microscopy analysis.

\section{REFERENCES}

1. Brennan NA, Coles MLC. Deposits and symptomatology with soft contact lens wear. Int Contact Lens Clinic 2000;27:75100 .

2. Gonzalez-Meijome JM, Lopez-Alemany A, Almeida JB, et al. Microscopic observation of unworn siloxane-hydrogel soft contact lenses by atomic force microscopy. J Biomed Mater Res B Appl Biomater 2006;76:412-418.

3. Gonzalez-Meijome JM, Lopez-Alemany A, Almeida JB, et al. Microscopic observations of superficial ultrastructure of unworn siloxane-hydrogel contact lenses by cryo-scanning electron microscopy. J Biomed Mater Res B Appl Biomater 2006;76:419-423.

4. Maldonado-Codina C, Morgan PB, Efron N, Canry JC. Characterization of the surface of conventional hydrogel and silicone hydrogel contact lenses by time-of-flight secondary ion mass spectrometry. Optom Vis Sci 2004;81:455-460.

5. Bhatia S, Goldberg EP, Enns JB. Examination of contact lens surfaces by Atomic Force Microscope (AFM). CLAO J 1997; 23:264-269.

6. Gonzalez-Meijome J, Lopez-Alemany A, Almeida J, Parafita M. Microscopic observations of silicone hydrogels with three different techniques. Invest Ophthalmol Vis Sci 2005;46:909.

7. Jones L, Senchyna M, Glasier MA, et al. Lysozyme and lipid deposition on silicone hydrogel contact lens materials. Eye Contact Lens 2003;29:S75-S79.

8. Baguet J, Sommer F, Duc TM. Imaging surfaces of hydrophilic contact lenses with the atomic force microscope. Biomaterials 1993; 14:279-284.

9. Kim SH, Opdahl A, Marmo C, Somorjai GA. AFM and SFG studies of pHEMA-based hydrogel contact lens surfaces in saline solution: Adhesion, friction, and the presence of noncrosslinked polymer chains at the surface. Biomaterials 2002;23:1657-1666.

10. Baguet J, Sommer F, Claudon-Eyl V, Duc TM. Characterization of lacrymal component accumulation on worn soft contact lens surfaces by atomic force microscopy. Biomaterials 1995;16:3-9.

11. Tighe B. Silicone hydrogels: Structure, properties and behaviour. In: Sweeney DF, editor. Silicone Hydrogels. ContinuousWear Contact Lenses. London: Butterword-Heinemann; 2004. pp 1-27.

12. Gonzalez-Meijome J, Lopez-Alemany A, Almeida J, Parafita M. Microscopic observations of silicone hydrogels with three different techniques. Invest Ophthalmol Vis Sci 2005;46: 909.
13. Lopez-Alemany A, Compan V, Refojo MF. Porous structure of purevision versus focus night \& day and conventional hydrogel contact lenses. J Biomed Mater Res 2002;63:319325.

14. Guryca V, Hobzova R, Pradny M, et al. Surface morphology of contact lenses probed with microscopy techniques. Cont Lens Anterior Eye 2007;30:215-222.

15. Gonzalez-Meijome J, Lopez-Alemany A, Jr., Almeida JB, Parafita MA. Consistency of surface analysis of siliconehydrogel contact lens polymers with Atomic Force Microscopy. Invest Ophthalmol Vis Sci 2006;47:2387.

16. Goldberg EP, Bhatia S, Enns JB. Hydrogel contact lens-corneal interactions: A new mechanism for deposit formation and corneal injury. CLAO J 1997;23:243-248.

17. Gonzalez-Meijome JM, Jorge J, Almeida JB, Parafita MA. Contact lens fitting profile in Portugal in 2005: Strategies for first fits and refits. Eye Contact Lens 2007;33:81-88.

18. Subbaraman LN, Glasier MA, Senchyna M, et al. Kinetics of in vitro lysozyme deposition on silicone hydrogel. PMMA, and FDA groups I, II, and IV contact lens materials. Curr Eye Res 2006;31:787-796.

19. Bontempo AR, Rapp J. Lipid deposits on hydrophilic and rigid gas permeable contact lenses. CLAO J 1994;20:242245.

20. Henriques M, Sousa C, Lira M, et al. Adhesion of Pseudomonas aeruginosa and Staphylococcus epidermidis to siliconehydrogel contact lenses. Optom Vis Sci 2005;82:446-450.

21. Merrit K, An YH. Factors influencing bacterial adhesion. In: An YH, Friedman RJ, editors. Handbook of Bacterial Adhesion: Principles, Methods and Applications. Totowa, NJ: Humana; 2000. pp 53-98.

22. Vermeltfoort PB, van der Mei HC, Busscher HJ, et al. Physicochemical factors influencing bacterial transfer from contact lenses to surfaces with different roughness and wettability. J Biomed Mater Res B Appl Biomater 2004;71:336-342.

23. Vermeltfoort PB, Rustema-Abbing M, de Vries J, et al. Influence of day and night wear on surface properties of silicone hydrogel contact lenses and bacterial adhesion. Cornea 2006;25:516-523.

24. Boles SF, Refojo MF, Leong FL. Attachment of Pseudomonas to human-worn, disposable etafilcon A contact lenses. Cornea 1992;11:47-52.

25. Duran JA, Refojo MF, Gipson IK, Kenyon KR. Pseudomonas attachment to new hydrogel contact lenses. Arch Ophthalmol 1987; 105:106-109.

26. Bruinsma GM, Rustema-Abbing M, de Vries J, et al. Influence of wear and overwear on surface properties of etafilcon A contact lenses and adhesion of Pseudomonas aeruginosa. Invest Ophthalmol Vis Sci 2002;43:3646-3653.

27. Michaud L, Giasson CJ. Overwear of contact lenses: Increased severity of clinical signs as a function of protein adsorption. Optom Vis Sci 2002;79:184-192.

28. Beattie TK, Tomlinson A, McFadyen AK. Attachment of Acanthamoeba to first- and second-generation silicone hydrogel contact lenses. Ophthalmology 2006;113:117-125.

29. Beattie TK, Tomlinson A, Seal DV Surface treatment or material characteristic: The reason for the high level of Acanthamoeba attachment to silicone hydrogel contact lenses. Eye Contact Lens 2003;29:S40-S43. 